\title{
Velocity Profiles of Synthetic Jets using Piezoelectric Circular Actuators
}

\author{
Karla Mossi ${ }^{*}$ and Poorna Mane ${ }^{\dagger}$ \\ Virginia Commonwealth University, Richmond, VA, 23235 \\ Robert Bryant ${ }^{\ddagger}$ \\ NASA Langley Research Center, Hampton, VA, 23681
}

\begin{abstract}
The performance of systems involving a body in a fluid flow can be enhanced by manipulation of the body shape through flow control. Active flow control, the focus of this work, is achieved by energizing low-momentum regions at the wall by tangential blowing using air. One mechanism for blowing air into this region is through synthetic jets. They are devices that push air out from a fixed orifice or a slit in the form of a jet. The jets are usually created using compressed air or an electromechanically driven vibrating platform. To diminish complexity, reduce weight, and increase time response, piezoelectric actuators used as oscillating diaphragms are often used. This study concentrates on characterizing a synthetic jet using three types of piezoelectric actuators as circular mechanical diaphragms: (1) pre-stressed curved metallic Unimorph or Thunder, (2) Bimorphs, and (3) Radial Field Diaphragms, RFD. The diaphragm is clamped around its perimeter, so that when voltage is applied to the device, it oscillates and a jet is pushed out an orifice perpendicular to the actuator. Maximum synthetic jet velocity into quiescent flow was monitored when varying frequencies, and driving waveforms of the diaphragms, as well as varying physical cavity characteristics. Results show that maximum velocity magnitude is markedly different with the different waveforms especially a sine waveform which produces the weakest jet. Changing the jet exit from a rectangular slot to a circular orifice produces a more uniform velocity profile independently of actuator and waveform type. Maximum velocity is recorded at a fixed distance from the orifice ( $\mathrm{z}$-axis) at various positions along the orifice ( $x$-axis). Regardless of the orifice shape used, the velocity profiles of the jets are bell shaped. To identify these factors a fractional factorial design of experiments was performed individually on each diaphragm. The results obtained were further verified using regression analysis. Results indicate that depending on the diaphragm utilized these factors may be different. This type of study can be extended to analyze other parameters that are significant to the successful implementation of these devices such as back pressure and cavity shape.
\end{abstract}

\section{Nomenclature}

$\begin{array}{ll}A & =\text { Actuator } \\ \mathrm{a} & =\text { Orifice Area } \\ C_{H} & =\text { Cavity Height } \\ D_{o} & =\text { Orifice diameter } \\ E & =\text { Field } \\ f & =\text { Frequency of the applied AC signal } \\ F_{z} & =\text { Applied waveform } \\ l & =\text { Slit Length } \\ w & =\text { Slit Width } \\ V_{p p} & =\text { Peak to Peak Voltage (no DC bias) }\end{array}$

* Assistant Professor, Mechanical Engineering, 601 West Main St, P.O. Box 843015, Richmond, VA, 23284, AIAA Member.

${ }^{\dagger}$ Graduate Student, Mechanical Engineering, 601 West Main St, P.O. Box 843015. Richmond, VA, 23284.

‡ Senior Chemical Engineer NASA Langley Research Center, MS 226, Hampton, VA, 23861. 


$$
\begin{array}{ll}
V_{z} & =\text { Jet Velocity } \\
\bar{V}_{z-\max } & =\text { Maximum Average Jet Velocity } \\
\bar{V}_{z} & =\text { Average Jet Velocity } \\
\Delta \text { Factors } & =\text { Average Factor Effect Size }
\end{array}
$$

\section{Introduction}

$\mathrm{T}$ The ability to manipulate a flow field through active flow control is of great technological importance. Active flow control has the potential benefits of improving maneuverability and decreasing fuel consumption leading to increased range and payload, and reduced noise. ${ }^{1,2}$

Flow control is utilized to delay or induce transition, to suppress or increase turbulence, or to prevent or advance separation. These techniques lead to drag reduction, lift enhancement, mixing augmentation, and noise suppression. ${ }^{3,4}$ Active flow control can be achieved using synthetic jet actuators ${ }^{5}$ and by means of oscillatory blowing techniques. ${ }^{6,7}$ They manipulate the physically evolving flow by introducing energy thereby changing the flow field. To introduce this energy and in terms of physical implementation synthetic jets are more beneficial over oscillatory blowing techniques. In the later case, additional supply lines are required which deliver air from a supply source to the flow control area. This increases the complexity, cost and overall weight of the system. Synthetic jets are compact, efficient and additional plumbing is not required making them lighter.

Synthetic jets use an oscillating diaphragm, inside a cavity, to generate a jet through an orifice in the cavity ${ }^{8}$. As the diaphragm oscillates flow enters and exits the cavity through the orifice. During the injection cycle fluid is drawn in to the cavity from the area outside the cavity surrounding the orifice. In the expulsion cycle the fluid is forced out of the cavity forming a train of vortex rings. Some of the vortices have enough momentum to prevent reentrainment into the cavity forming a jet. Even though there is no input of mass, the resulting momentum of the system is non-zero. Each cycle of the diaphragm causes a change in the mass of the cavity due to its movement but the net change in mass is zero hence the name of zero-net-mass-flux-jets ${ }^{9}$. A range of flow control results have been achieved using the synthetic jet actuator including thrust vectoring, mixing enhancement, separation control and virtual surface shaping., ${ }^{50-15}$ These applications illustrate the great potential for this type of actuator to be applied to air vehicles for aerodynamic control.

A key component of the synthetic jet is the oscillating diaphragm or actuator. In earlier studies by Smith and Glezer single piezoelectric discs were used as the active diaphragms. ${ }^{16}$. Piezoelectric discs satisfy most of the requirements of synthetic jet diaphragms such as; micro scale displacement, fast time response, wide bandwidth, light weight, reliability and also low power consumption. ${ }^{17}$ Less fragility and more durability are desired for this particular application. In the past decade, a number of piezoelectric composites have been developed which exhibit enhanced capabilities and durability as compared to a single piezoelectric discs. Piezoelectric actuators such as moonies, ${ }^{18}$ rainbows, ${ }^{19,20}$, unimorphs, ${ }^{21}$ thunders ${ }^{22-25}$ and bimorphs ${ }^{26,27}$ have been investigated and their properties and behavior documented. These actuators have shown to produce higher displacement amplitudes together with enhanced durability. In this study, piezoelectric composites are utilized as the active elements or the oscillating diaphragms.

The characterization of the diaphragms used for synthetic jets involves various factors. These factors are the type of the diaphragm, the size of the cavity, the shape of the orifice and the driving waveform, voltage and frequency. The response chosen to asses the influence of the above factors is the average peak velocity of the jet.

The three diaphragms used in the present study are Thunder, Bimorph, and Radial Field Diaphragms or RFD. ${ }^{28,29}$ The actuators are different from each other but share two common characteristics, their diameters of $6.35 \mathrm{~cm}$ and the active material element used in their construction. In previous studies Mossi and Bryant have documented the displacement performance of these devices for the current application. ${ }^{30}$ The geometry and overall free displacement characteristics of these piezoelectric actuators allow for direct implement into a simple design. ${ }^{31,32}$ The objective of this study is to quantify the effects any of the five mentioned factors have on the peak synthetic jet velocity. To that end, a design of experiments is performed on these parameters such that statistical analysis can be utilized to analyze the significance of the individual factors and the interactions among them.

\section{Experimental Procedure}

Three types of diaphragms used are the Thunder, Bimorph, and the RFD. The Thunder ${ }^{\circledR}$ is a pre-stressed curved Unimorph composed of three layers, a top perforated copper layer $0.0254 \mathrm{~mm}$ thick, a middle piezoelectric layer of thickness $0.254 \mathrm{~mm}$, and a bottom $0.254 \mathrm{~mm}$ thick layer of stainless steel. The layers are laminated with a high temperature polyimide adhesive. ${ }^{33}$ The resulting actuator is saddle shaped with a capacitance of $100 \mathrm{nF}$. The 
Bimorph, model T216-A4NO-573X is manufactured by Piezoelectric Systems Inc. and consists of two bonded piezoelectric discs with nickel electrodes having a total thickness of $0.41 \mathrm{~mm}$ and capacitance of $130 \mathrm{nF}$. The RFD is a new actuator developed by NASA Langley Research Center which consists of a piezoelectric layer laminated in between Kapton ${ }^{\circledR}$ film with etched inter-circulating copper electrodes. ${ }^{34}$ This electrode design is responsible for the devices low capacitance, $14 \mathrm{nF}$, and its characteristic high displacement and dome topography. The piezoelectric ceramic used in each of these diaphragms is a soft PZT type 5A.

The experimental setup for a cavity with a circular orifice is shown in Figure 1. This setup allows variations in cavity height and orifice shapes and dimensions. The two cavities have overall dimensions of $89.0 \times 89.0 \times 19.1$ $\mathrm{mm}$ and $89.0 \times 89.0 \times 15.1 \mathrm{~mm}$, which correspond to cavity heights of $9.5 \mathrm{~mm}$ and $5.5 \mathrm{~mm}$ respectively. This cavity height, $\mathrm{C}_{\mathrm{H}}$, is measured from the diaphragm to the orifice exit. The cavity housing is composed of two identical rectangular Plexiglas ${ }^{\mathrm{TM}}$ pieces with a circular aperture and a cover plate with an orifice. The two plastic pieces have a $3.18 \mathrm{~mm}$ deep circular grooves along the circumference of the aperture. The diaphragm is placed in this groove between the two pieces with neoprene rubber around the perimeter of the diaphragm on either side. Seven $3.18 \mathrm{~mm}$ screws hold the two plastic housings and the cover plate together and clamp the actuator in place. Two circular orifices were used having approximate diameters of $2.0 \mathrm{~mm}$ (small) and $3.67 \mathrm{~mm}$ (big). Another orifice shaped as a rectangular slit (Figure 2) having dimensions of $34 \mathrm{mmX} 0.75 \mathrm{~mm}$ was also used.

The assembled cavity was mounted onto an adjustable height gauge, with the actuators surface perpendicular to the hot-wire anemometer used to measure velocity of the jet from the orifice. The velocities were measured in the $\mathrm{z}$ direction at distances of approximately $0.64 a$ and $0.2 a$ in the case of the small and big circular orifices respectively and at $0.08 a$ for the slit where $a$ is the area of the orifice. The peak velocity of the jet formed in quiescent air is measured at several locations along the diameter of the circular orifice and the length of the slit. The driving waveforms, voltages and frequencies were varied for two levels depending on the type of actuator. In order to prevent the electrical failure of the diaphragms, the voltages were kept below their allowable maximum driving fields. Frequency ranges were dependent on the properties of the diaphragms, and the power supply capabilities. The applied frequencies were below the respective resonant frequencies.

The equipment used in the experiments included a 9350L LeCroy oscilloscope, PZD700 TREK amplifier, HP33120 signal generator, a TSI 1210-T1.5 hot-wire anemometer, an IFA 100 signal conditioner and an Endevco 8510 B-2 dynamic pressure transducer. All the equipment was controlled and monitored using LabView ${ }^{\circledR}$ software through a PC equipped with a National Instruments data acquisition card.

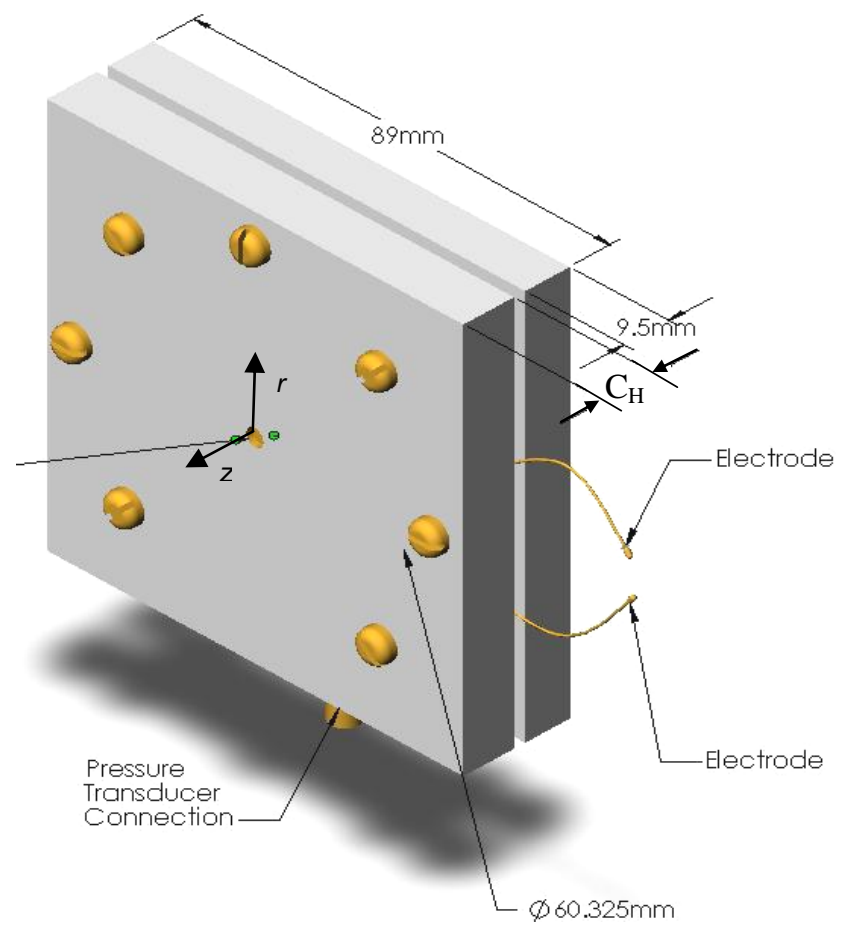

Figure 1 Cavity with a Circular orifice 


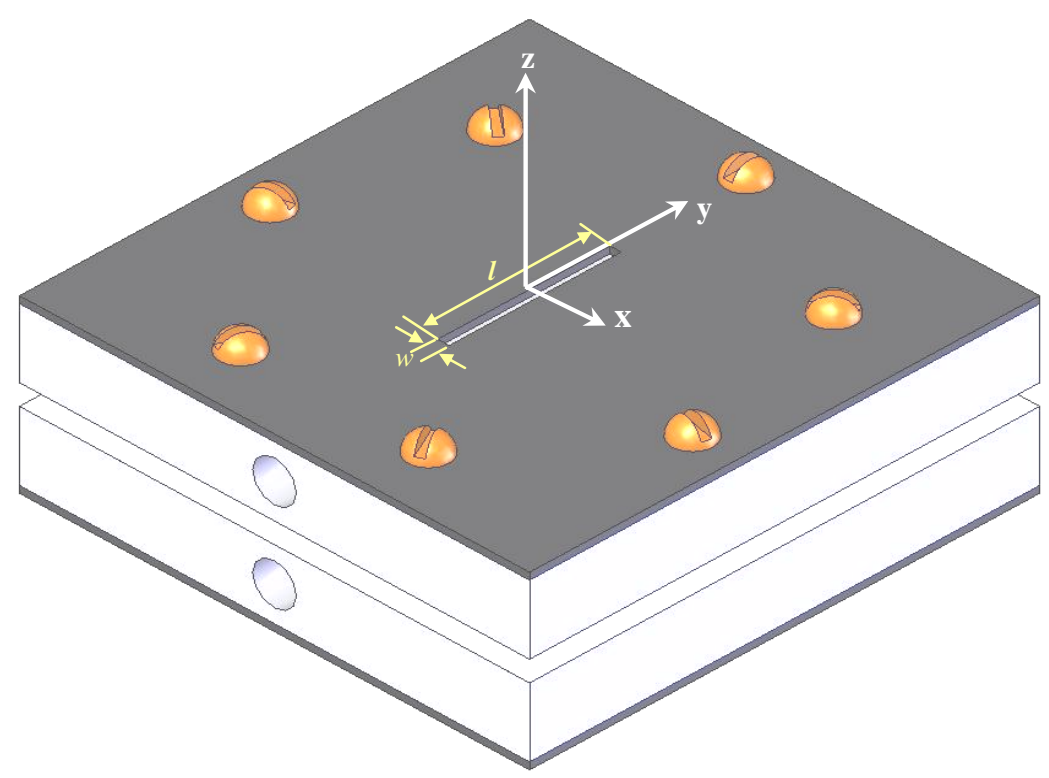

Figure 2 Cavity with a Rectangular Slit

\section{Design of Experiments}

As mentioned in the previous section, piezoelectric synthetic jets may be influenced by many factors such as driving signal and cavity characteristics. These factors (drive frequency, voltage, cavity size etc.) may be particular to each type of piezoelectric actuator and the effect and interaction between these factors might be significant when characterizing synthetic jet velocity. In this case a factor screening experiment for each actuator could facilitate the study of the effects of the factors on a single response, peak jet velocity ${ }^{35}$ at the center of the orifice. For these reasons, a design of experiments based on testing each factor at two levels, low and high was formulated. For the first stage of screening experiments, five factors were considered for each actuator, applied waveform $\left(F_{z}\right)$, voltage $(E)$, frequency $(f)$, orifice size $\left(D_{0}\right)$, and cavity height $\left(C_{H}\right)$. A full factorial design requires a $2^{5}=32$ runs per actuator, making a total of 96 runs without center points or repetitions. Instead a fractional factorial design, $2^{(5-1)}$, requiring a total of 16 observations per actuator was utilized. The factors, shown in Table 1, have a resolution $\mathrm{V}$ which indicates that no main effects are confounded with any 2-factor interactions or 3-factor interactions; main effects are confounded with four-factor interactions only.

Table 1 Factor Distribution

\begin{tabular}{cccccc}
\hline Factors & Symbol & $\begin{array}{c}\text { Low Level } \\
(-)\end{array}$ & $\begin{array}{c}\text { High Level } \\
(+)\end{array}$ & Units & $\begin{array}{c}\text { Variable } \\
\text { Type }\end{array}$ \\
\hline Applied Waveform & $F_{z}$ & Sawtooth $(-1)$ & Sine $(+1)$ & None & Discrete \\
Applied Field & $E$ & Low $(-1)$ & High $(+1)$ & $\mathrm{V}_{\mathrm{pp}}$ & Continuous \\
Frequency & $f$ & $32(-1)$ & $50(+1)$ & $\mathrm{Hz}$ & Continuous \\
Orifice Size & $D_{0}$ & $2.2(-1)$ & $3.7(+1)$ & $\mathrm{mm}$ & Continuous \\
Cavity Height & $C_{H}$ & $5.5(-1)$ & $9.55(+1)$ & $\mathrm{mm}$ & Continuous \\
\hline
\end{tabular}

All the factors shown in Table 1 are considered individually for each actuator and results are discussed in the following sections. The runs and their characteristics are shown in Table 2 so that the influence of each factor can be assessed independently. Equation 1 shown below quantifies the effect of each factor per run. 


\section{Table 2 Experimental Design}

\begin{tabular}{|c|c|c|}
\hline $\begin{array}{l}\text { Run } \\
\text { No. }\end{array}$ & Factors $_{i}$ & Response $_{j}$ \\
\hline$j$ & $F_{z} E \quad f \quad f \quad D_{0} C_{H}$ & $Y$ \\
\hline 1 & \begin{tabular}{|cccc}
-1 & -1 & -1 & $-1+1$
\end{tabular} & $y_{1}$ \\
\hline 2 & $+1 \quad-1-1 \quad-1 \quad-1$ & $y_{2}$ \\
\hline 3 & $-1+1-1 \quad-1 \quad-1$ & $y_{3}$ \\
\hline 4 & $+1+1-1-1+1$ & $y_{4}$ \\
\hline 5 & $-1 \quad-1+1 \quad-1 \quad-1$ & $y_{5}$ \\
\hline 6 & $+1 \quad-1+1 \quad-1+1$ & $y_{6}$ \\
\hline 7 & $-1+1+1-1+1$ & $y_{7}$ \\
\hline 8 & $+1+1+1 \quad-1 \quad-1$ & $y_{8}$ \\
\hline 9 & $\begin{array}{lllll}-1 & -1 & -1 & +1 & -1\end{array}$ & $y_{9}$ \\
\hline 10 & $+1-1-1+1+1$ & $y_{10}$ \\
\hline 11 & $-1+1-1+1+1$ & $y_{11}$ \\
\hline 12 & $+1+1-1+1-1$ & $y_{12}$ \\
\hline 13 & $-1-1+1+1+1$ & $y_{13}$ \\
\hline 14 & $+1-1+1+1 \quad-1$ & $y_{14}$ \\
\hline 15 & $-1+1+1+1-1$ & $y_{15}$ \\
\hline 16 & $+1+1+1+1+1$ & $y_{16}$ \\
\hline & ors $_{i}=\frac{1}{2} \sum_{j=1}^{n=16} y_{j}$ & \\
\hline
\end{tabular}

Where $\Delta$ Factor represents the average size of the factor effect, $y$ is the response, so that the effect size of $F_{z}$ becomes equation 2 , where $\mathrm{n}$ is the number of runs.

$$
\begin{aligned}
& \Delta \text { Factor }_{i}=\Delta F_{z}=\frac{1}{2} \cdot\left[y_{1} \cdot F_{z_{1}}+y_{2} \cdot F_{z_{2}+\ldots+} y_{16} \cdot F_{z_{16}}\right] \\
& \Delta F_{z}=\frac{1}{2 n} \cdot\left[y_{1} \cdot(-1)+y_{2} \cdot(+1)+\ldots+y_{16} \cdot(+1)\right]
\end{aligned}
$$

Similarly, the size of the effects of each factor can be quantified. An additional analysis consists of an empirical regression equation of all the main factors assuming that interaction effects are not significant. The model is of the form shown in equation 3 ,

$$
y_{i}=\mu+\sum \beta_{i} \cdot \text { Factor }_{j}
$$

Where $\mu$ represents the sample mean of the response, $\beta$ represents the coefficients for each factor considered. Statistical results are used to assess the validity and influence of the particular effect on the response. The analysis for each actuator is presented in the following sections.

\section{A. Thunder}

For the thunder, the factors were varied as shown in Table 1 with fields tested at $250 \mathrm{~V}_{\mathrm{pp}}$ and $400 \mathrm{~V}_{\mathrm{pp}}$ for low and high levels respectively. By following the experimental design described, the average effect size for the waveform, $F_{z}$, is -7.78 ; for the applied field, $E$ is 0.22 ; for frequency, $f$, is 2.77 ; for orifice diameter, $D_{0}$, is -0.57 ; and for cavity 
height, $C_{H}$, is -7.7. These results are illustrated and corroborated by taking the average of each considered factor and plotting the response as shown in Figures 3a-e.

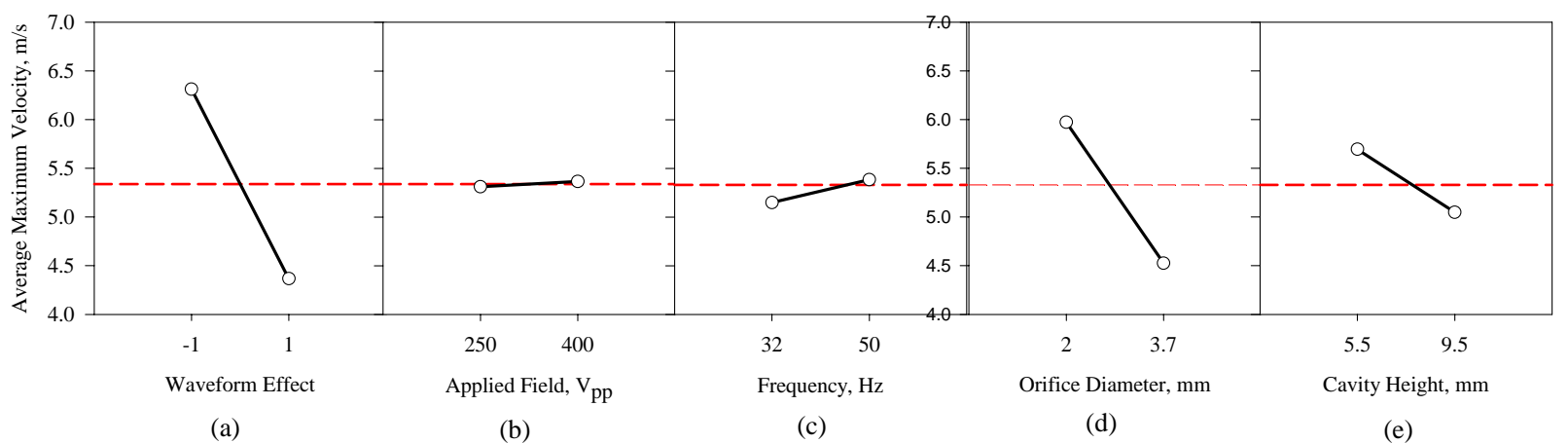

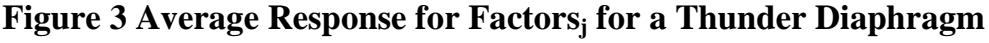

A more complete evaluation of the relevance of these factors can be performed using a regression analysis. The obtained results in an equation are shown in Equation 4.

$$
y_{i}=\beta_{0}+\beta_{1} \cdot F_{Z}+\beta_{2} \cdot E+\beta_{3} \cdot f+\beta_{4} \cdot D_{0}+\beta_{5} \cdot C_{H}
$$

Where $y$ represents the average maximum velocity in $\mathrm{m} / \mathrm{s}$, and the $\beta$ coefficient values are shown in the table 3 below.

Table 3 Regression Analysis for a Thunder Device

\begin{tabular}{|c|c|c|c|c|c|c|}
\hline \multicolumn{2}{|c|}{ SUMMARY OUTPUT } & & & & & \\
\hline \multicolumn{2}{|c|}{ Regression Statistics } & & & & & \\
\hline Multiple R & 0.96191 & & & & & \\
\hline R Square & 0.92528 & & & & & \\
\hline $\begin{array}{l}\text { Adjusted R } \\
\text { Square }\end{array}$ & 0.90924 & & & & & \\
\hline Standard Error & 2.39808 & & & & & \\
\hline Observations & 86 & & & & & \\
\hline \multicolumn{7}{|l|}{ ANOVA } \\
\hline & $d f$ & SS & $M S$ & $F$ & Significance F & \\
\hline Regression & 5 & 5767.91 & 1153.6 & 200.5951 & $9.76358 \mathrm{E}-44$ & \\
\hline Residual & 81 & 465.81 & 5.8 & & & \\
\hline \multirow[t]{2}{*}{ Total } & 86 & 6233.73 & & & & \\
\hline & Coefficients & $\begin{array}{c}\text { Standard } \\
\text { Error }\end{array}$ & $t$-Stat & $P$-value & Lower 95\% & Upper 95\% \\
\hline$\beta_{1}$ & -0.53600 & 0.26106 & -2.05314 & $4.329 \mathrm{E}-02$ & -1.055424 & -0.01657 \\
\hline$\beta_{2}$ & 0.01787 & 0.00302 & 5.91750 & 7.510E-08 & 0.011861 & 0.02388 \\
\hline$\beta_{3}$ & 0.07616 & 0.00925 & 8.23718 & $2.559 \mathrm{E}-12$ & 0.057762 & 0.09455 \\
\hline$\beta_{4}$ & 1.22693 & 0.53098 & 2.31071 & 2.339E-02 & 0.170454 & 2.28340 \\
\hline$\beta_{5}$ & -0.71120 & 0.11879 & -5.98696 & $5.590 \mathrm{E}-08$ & -0.947560 & -0.47484 \\
\hline
\end{tabular}


The results show that all coefficients are significant with p-values less than 0.05 , on producing a maximum jet velocity for the Thunder actuator. Coefficients for the waveform, the orifice diameter, and cavity height have a higher effect on the jet velocity than the applied field and frequency as confirmed by Figures 3a through 3e and the regression model.

\section{B. Bimorph}

The results for the Bimorph differ from the Thunder actuator in that the influence of all the factors is more pronounced. This can be observed in Figure 4 and is quantified with equation 2; the average effect size for the waveform, $F_{z}$, is -8.86 ; for the applied field, $E$ is 3.34 ; for frequency, $f$, is 4.38 ; for orifice diameter, $D_{0}$, is -4.51 ; and for cavity height, $C_{H}$, is -4.01 .

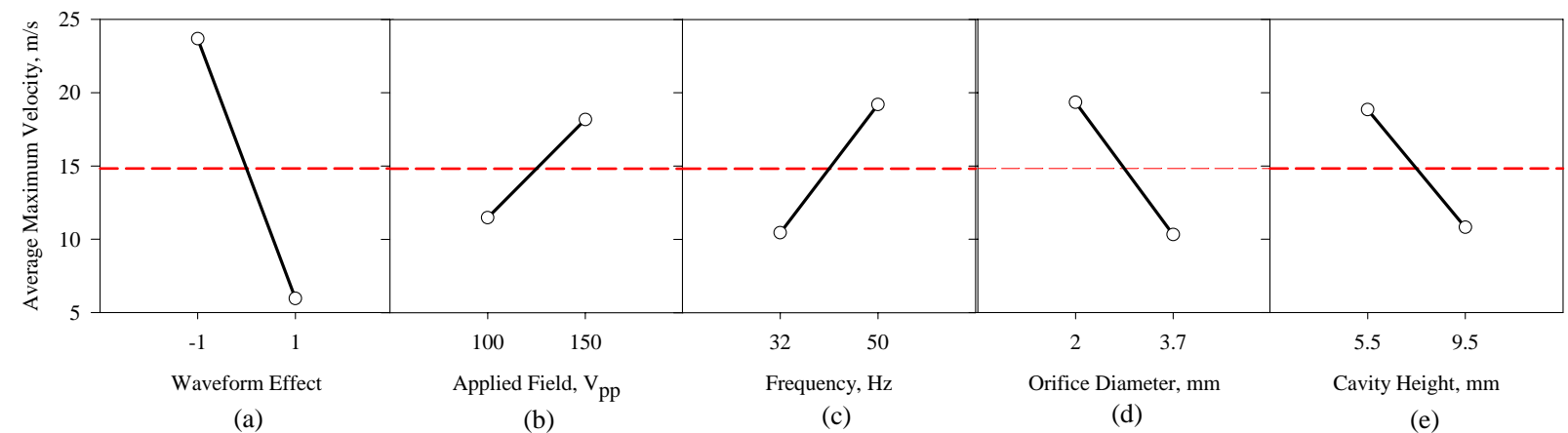

Figure 4 Average Response of Factors ${ }_{j}$ for a Bimorph Actuator

The results of the effects are also quantified with a regression equation with the same parameters than described for Thunder devices with $p$-values less than 0.05 as shown in Table 4 .

Table 4 Regression Analysis for a Bimorph Device

\begin{tabular}{|c|c|c|c|c|c|c|}
\hline \multicolumn{3}{|c|}{ SUMMARY OUTPUT } & & & & \\
\hline \multicolumn{3}{|c|}{ Regression Statistics } & & & & \\
\hline \multicolumn{2}{|c|}{ Multiple R } & 0.988724454 & & & & \\
\hline \multicolumn{2}{|c|}{ R Square } & 0.977576046 & & & & \\
\hline \multicolumn{2}{|c|}{ Adjusted R Square } & 0.963782428 & & & & \\
\hline \multicolumn{2}{|c|}{ Standard Error } & 4.473903926 & & & & \\
\hline \multicolumn{2}{|c|}{ Observations } & 84 & & & & \\
\hline \multicolumn{7}{|c|}{ ANOVA } \\
\hline \multicolumn{3}{|c|}{$d f$} & SS & MS & $F$ & Significance F \\
\hline \multirow{3}{*}{\multicolumn{2}{|c|}{$\begin{array}{l}\text { Regression } \\
\text { Residual } \\
\text { Total } \\
\end{array}$}} & 5 & 68934.83739 & 13786.96748 & 688.8036563 & $5.44613 \mathrm{E}-63$ \\
\hline & & 79 & 1581.249491 & 20.01581634 & & \\
\hline & & 84 & 70516.08688 & & & \\
\hline \multicolumn{2}{|c|}{ Coefficients } & $\begin{array}{c}\text { Standard } \\
\text { Error }\end{array}$ & t Stat & P-value & Lower 95\% & Upper 95\% \\
\hline $\mathrm{x} 1$ & -14.70442 & 0.488142938 & 30.123190315 & 4.5759E-45 & -15.676046816 & 13.732798422 \\
\hline $\mathrm{x} 2$ & 0.10566 & 0.043646455 & 2.420887684 & $1.7777 \mathrm{E}-02$ & 0.018787071 & 0.192539260 \\
\hline $\mathrm{x} 3$ & 0.13242 & 0.017606312 & 7.521068962 & $7.4234 \mathrm{E}-11$ & 0.097373800 & 0.167462774 \\
\hline $\mathrm{x} 4$ & -91.43331 & 20.806050624 & -4.394553673 & 3.4175E-05 & 132.846713337 & 50.019899062 \\
\hline $\mathrm{x} 5$ & 34.70573 & 8.686573012 & 3.995330936 & $1.4404 \mathrm{E}-04$ & 17.415543098 & 51.995924669 \\
\hline
\end{tabular}




\section{Radial Field Diaphragm}

In the case of the Radial Field Diaphragms, the parameters show higher effects than the values shown by the other two actuators. The results show the value of the effects to be $F_{z},-1.02, E$ is2.27, $f$ is 2.36, $D_{0}$ is -1.52 ; and $C_{H}$ is -1.6. A regression however, did not produce statistically significant results and further tests with these actuators are necessary.

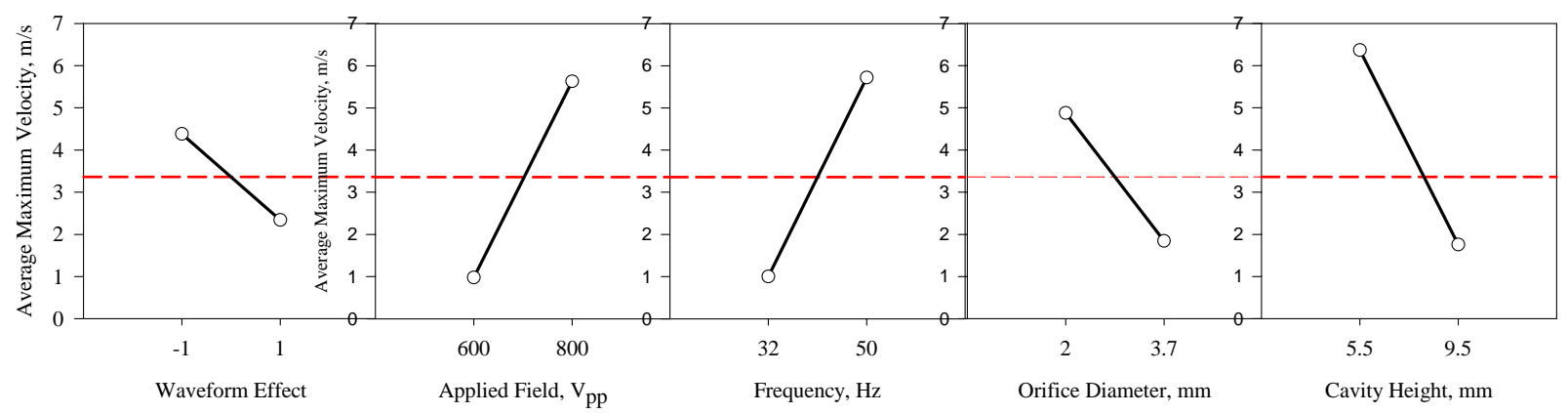

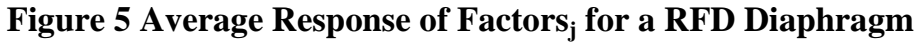

\section{Results and Discussion}

A typical velocity profile using a sinusoidal waveform for a Thunder device at $400 \mathrm{Vpp}$, and $50 \mathrm{~Hz}$ with a smaller cavity is shown in Figure 6. The bell-shaped curve of the profile is typical of all the actuators. In previous studies Carter and Soria measured similar profiles while studying the evolution of circular synthetic jets formed using a piston. ${ }^{36}$

(a)

(b)

(c)

(d)

(e)

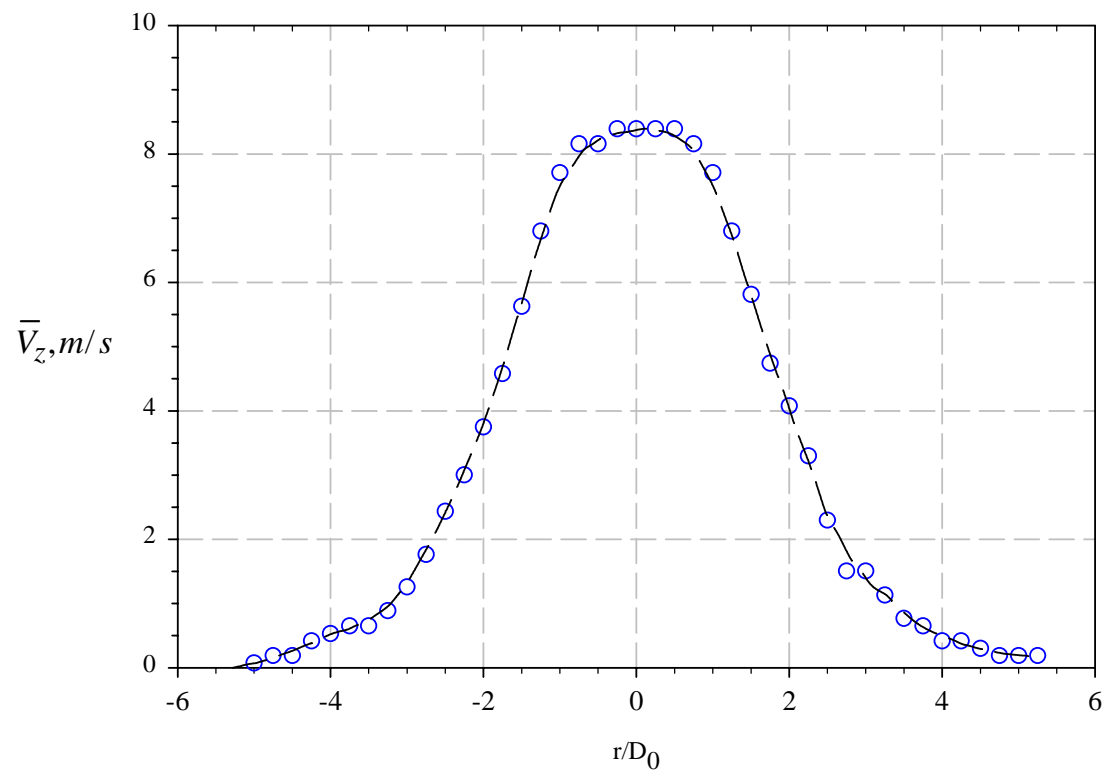

Figure 6 Typical Velocity Profile for a Thunder Diaphragm using a 400Vpp sinusoidal waveform, at $50 \mathrm{~Hz}$, thorough a circular orifice 
In the case of a saw-tooth waveform, a typical; velocity profile has a similar shape to the one obtained with a sine wave. However the overall magnitudes of the velocities obtained are higher when using a saw-tooth independently of the actuator type utilized. A curve is shown in Figure 7.

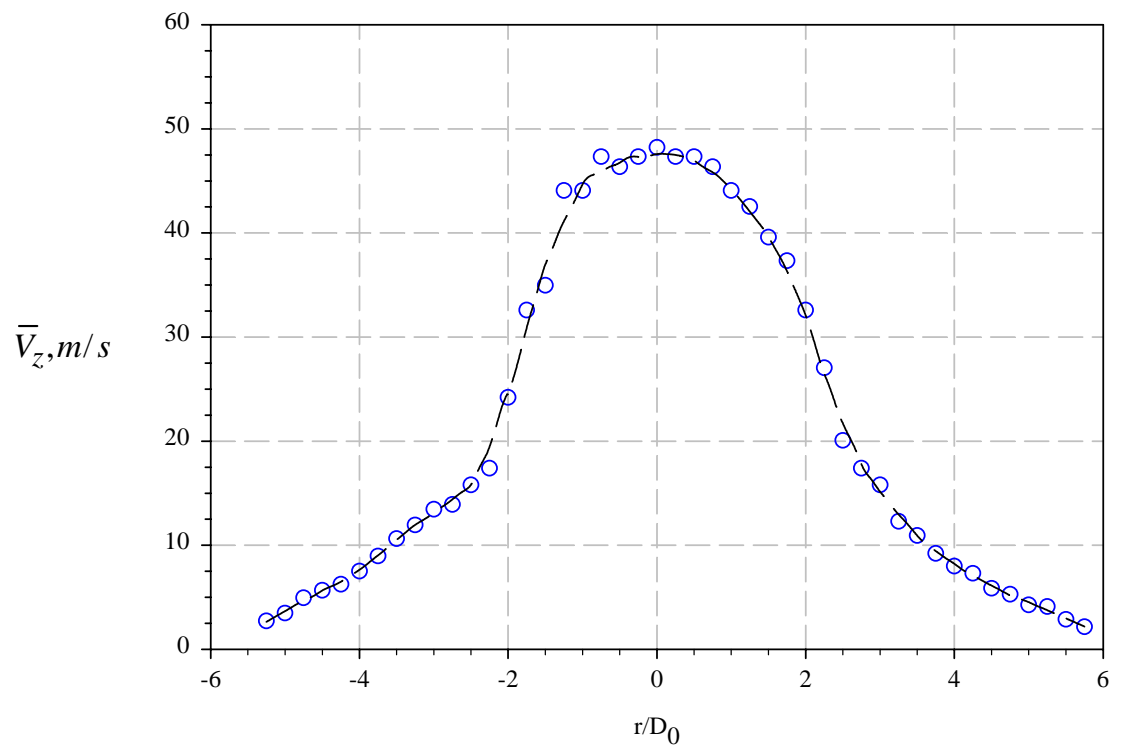

Figure 7 Typical Velocity Profile using a Saw-tooth waveform for a Bimorph at 150Vpp and $50 \mathrm{~Hz}$

Figure 8 shows the profiles obtained with a Thunder at the two frequencies level used in the design of experiments described in the previous section. As concluded above the frequency does not have a significant effect on the velocity. Only a small difference in magnitude is seen in the profiles with both the curves forming a bell shaped curve as seen in other cases. These results further validate the results obtained in the design of experiments analysis. Similar trends are seen with Bimorphs and RFD with varying magnitudes.

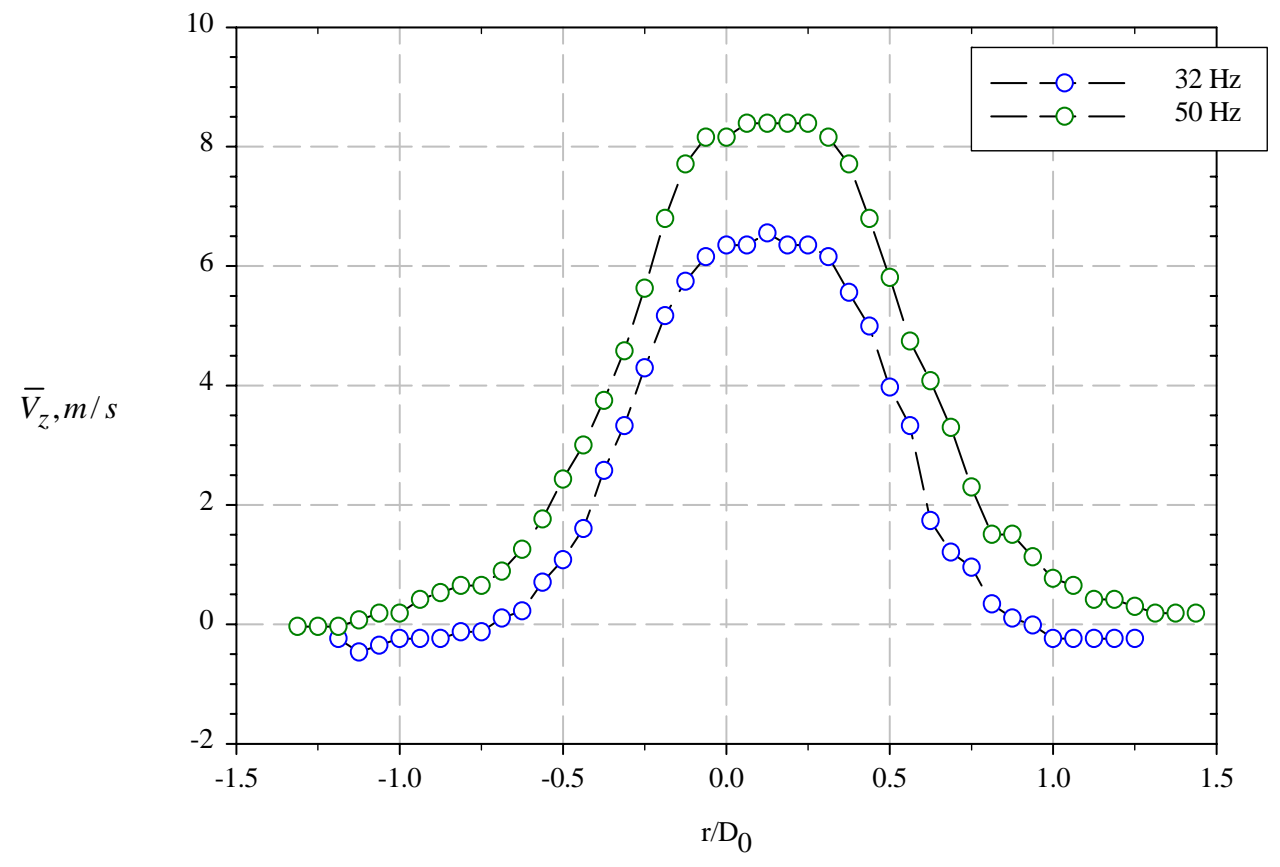

Figure 8 Velocity Profiles using a Sine wave for a Thunder at Different Frequencies

American Institute of Aeronautics and Astronautics 
Further experiments were conducted with the same cavity, but changing the orifice shape to a rectangular slit. The velocity profile in this case is approximately rectangular along the length of the slit as shown in Figure 9. Because of the non-uniformity observed in the profiles, the entire slit was mapped along the length, $y$-direction, and width, $\mathrm{x}$-direction as shown in figures 10a through 10f. Figure 10a shows one edge of the slit at $\mathrm{x}=-0.55 \mathrm{~mm}$ and figures $10 \mathrm{f}$ the other edge at $\mathrm{x}=0.55 \mathrm{~mm}$ with $10 \mathrm{~b}$ to $10 \mathrm{e}$ being intermediate locations along the width. The profiles at the two edges (10a and 10f) are mirror images of each other. These results are similar to the ones observed by Zhong et al. ${ }^{37}$

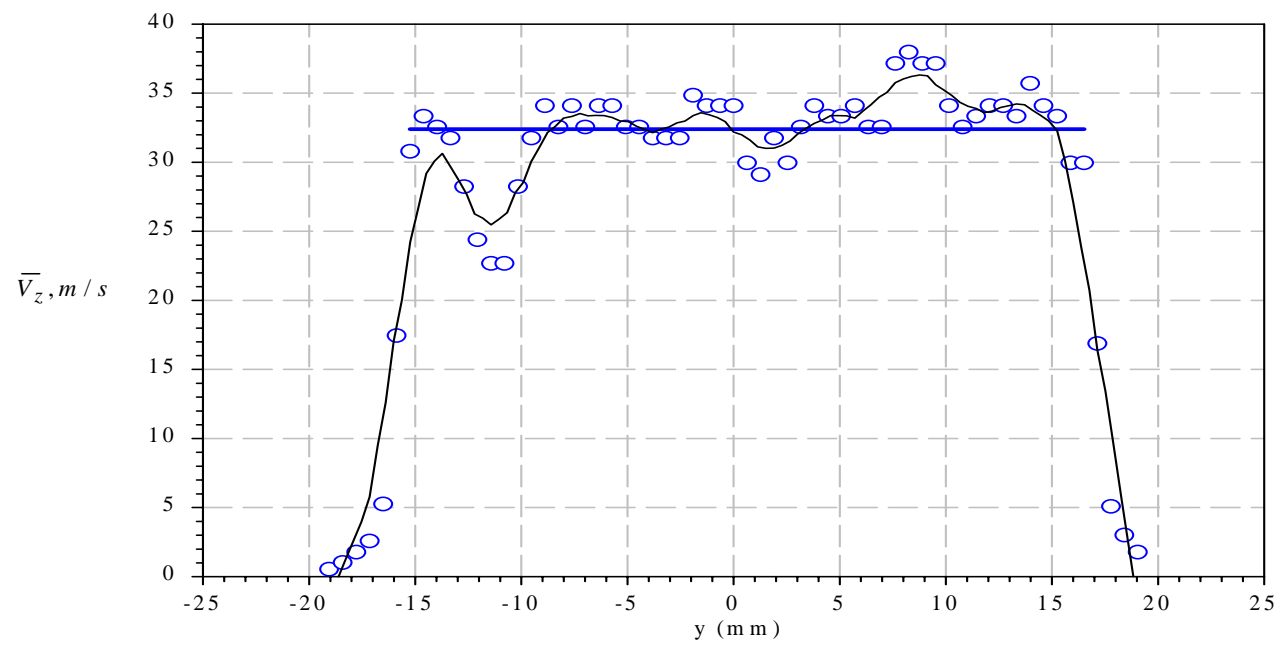

Figure 9 Typical Velocity Profile at $x=0 \mathrm{~mm}$ for a Bimorph actuator driven with a Sawtooth Waveform at 32
$\mathrm{~Hz}$ and $\mathbf{1 5 0 V}_{\mathrm{pp}}$

To evaluate the velocity obtained when utilizing a slit requires measurements of the velocity profile across the surface of the cavity or selected optimum locations for accurate and repeatable measurements. All the actuators provide similar profile shapes independent of cavity dimensions. Velocity magnitudes however, differ depending on the cavity height. The Bimorph actuator produced the highest velocity independently of cavity height, waveform or voltage. The biggest disadvantage this actuator showed under the tested conditions is it fragility and price. Thunder actuators and Radial Field Diaphragms were more durable and easy to handle event though their maximum velocities measured were always less than a Bimorph though not significantly. To overcome this obstacle, stacking devices such as the RFD and Thunder to obtain a synthetic jet, is a feasible alternative that might provide benefits such as added pressure capabilities such as the differentials experienced in flight conditions.

From the profiles measured along the slit of the cavity, it is evident that the location of the measurements is crucial when monitoring velocity profiles. Since the results are sensitive to location, one peak velocity measurement such as the one used for the circular orifice, does not constitute a measure of the performance of the diaphragms utilized. In order to assess the effects of frequency on the peak velocities obtained through a slit, measurements were taken at three locations along the length of the slit (y direction); the center of the slit, and at a distance of $10 \mathrm{~mm}$ above and below the center. Figure 11 shows the velocities obtained by averaging the values recorded at the three locations for a Bimorph. As seen in the figure a sine wave produces a gradual velocity increases such as the one observed with an orifice. However for a saw tooth waveform the velocities reach a steady condition after approximately $20 \mathrm{~Hz}$. This implies that after a point the velocity of the jet is not affected by frequency when a saw tooth waveform is used. This behavior of the jet could be significant while designing a device for flow control for specific applications. Similar behavior is seen with a Thunder device. The RFD on the other hand has a low frequency range and heat generated becomes an issue at higher frequencies and fields. Thus similar experiments could not be conducted, as the device was prone to damage. 


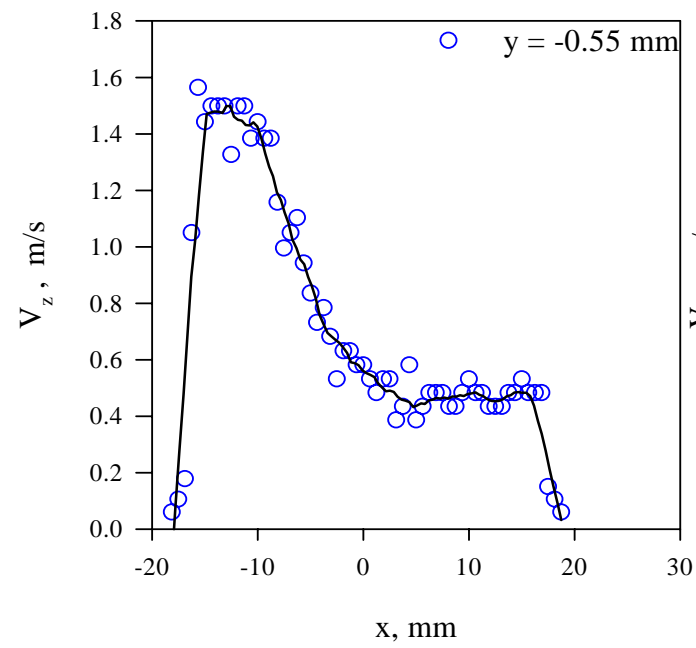

(a)

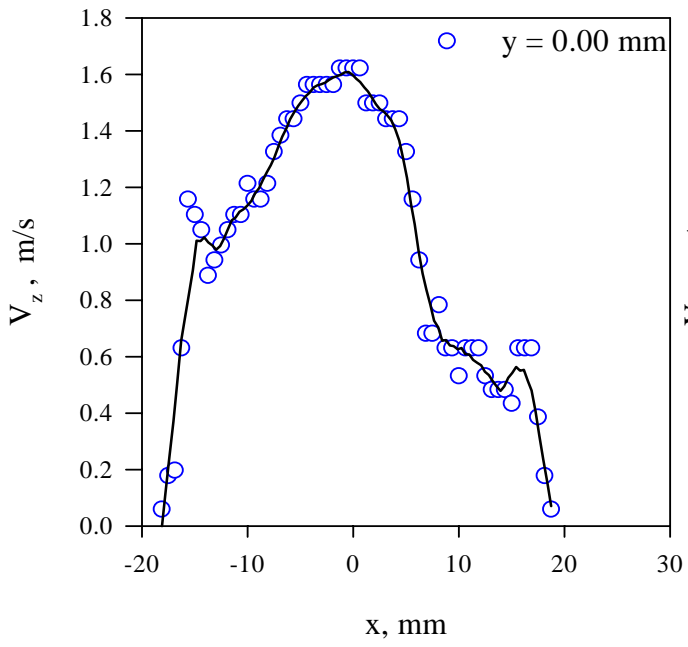

(c)

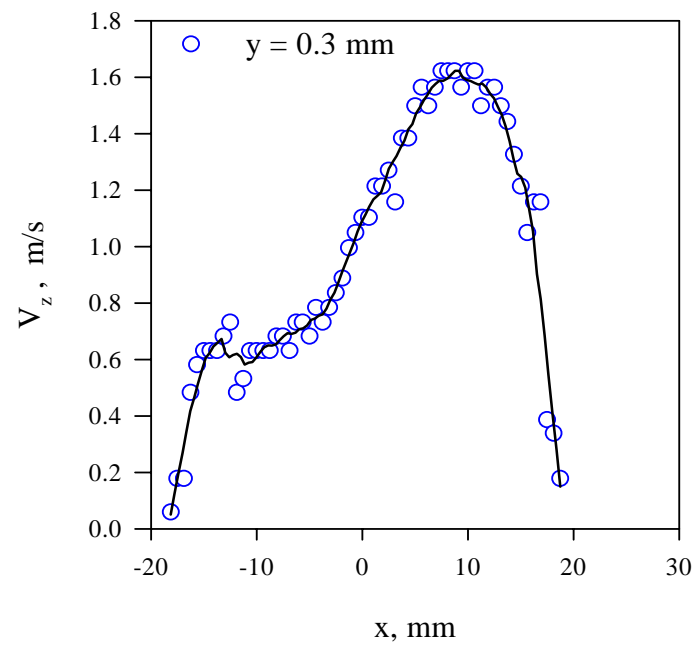

(e)

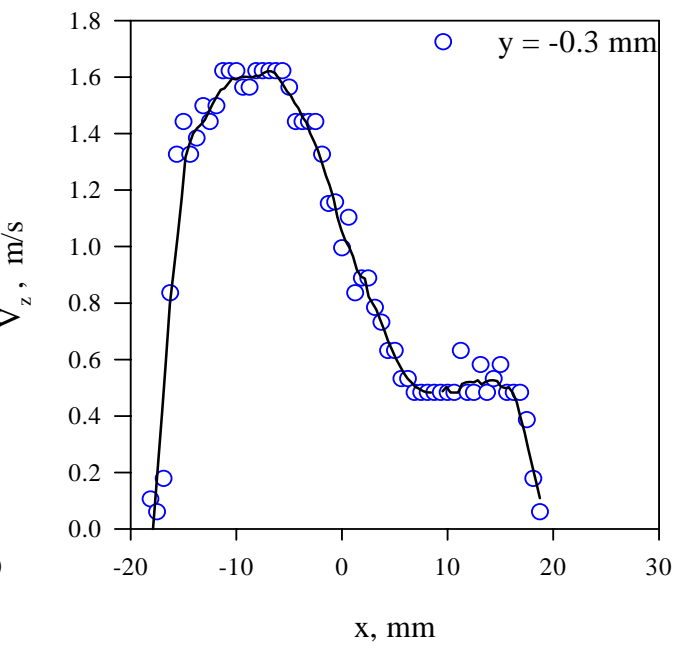

(b)

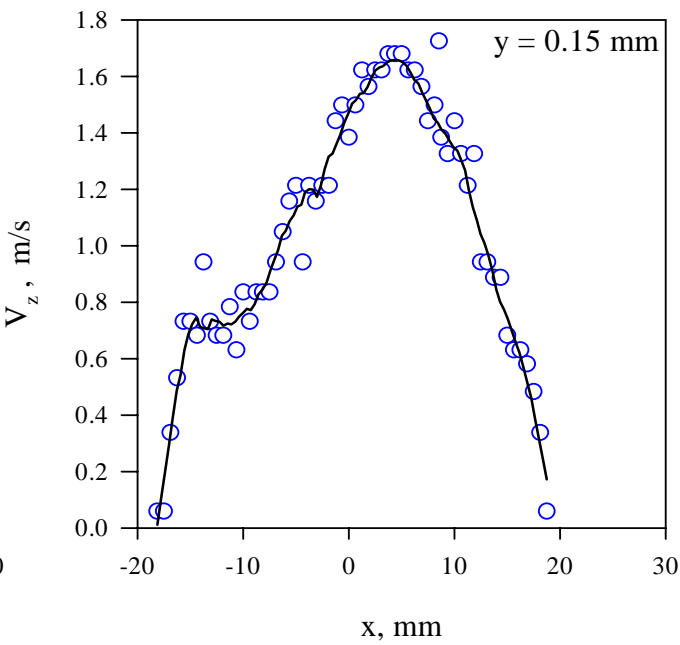

(d)

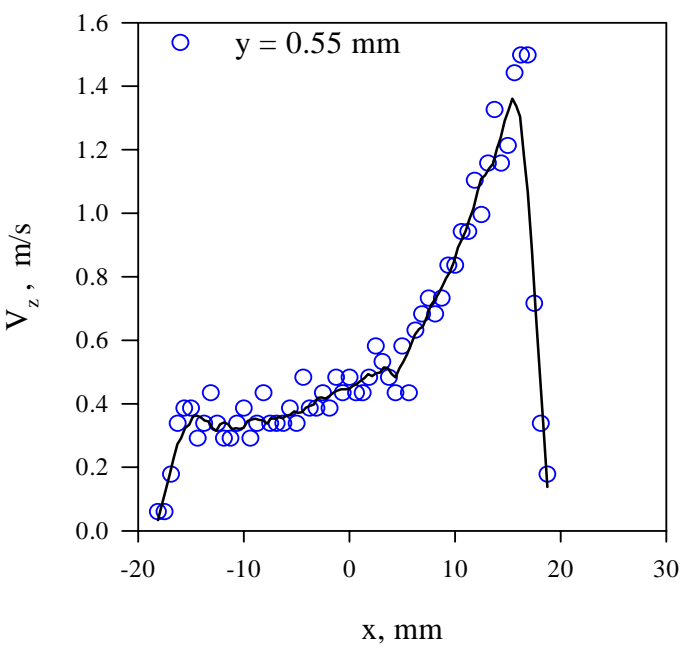

(f)

Figure 10 Velocity Profiles along the Slit Length 


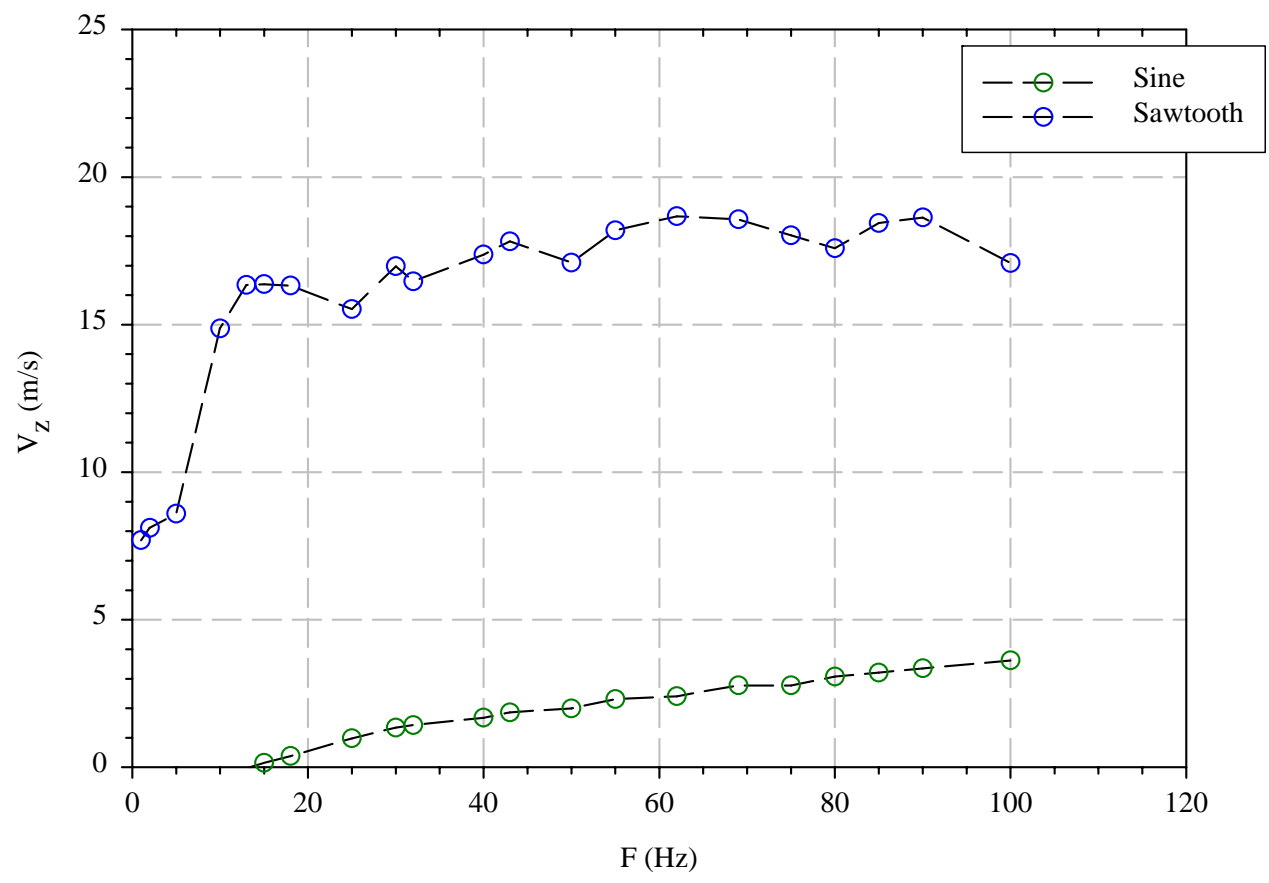

Figure 11 Frequency Effects on a Bimorph at 150Vpp

The analysis of experiments showed that the influence of the driving waveform is one of the biggest factors when analyzing the use of piezoelectric actuators as synthetic jets. Velocity profiles measured when a sinusoidal waveform were observed to be more uniform for both the slit and a circular orifice, though with lower magnitudes at the range of frequencies tested, less than $100 \mathrm{~Hz}$. The magnitude of the applied field to the actuators was not significant for the Thunder actuator, but was significant for the Bimorph and the Radial Field Diaphragms. Frequency was significant for the Bimorph and Radial Field Diaphragms but not for Thunder. The last two factors that depend on cavity geometry were significant for all the three actuators. In addition, the analysis of experiments indicates the path for obtaining optimum results, in this case, maximum jet velocity. Results of the factor analysis for the circular orifice can be expressed as shown in Equations 5.

$$
\begin{aligned}
& \text { Thunder }=\text { Thunder }\left[F_{Z}, D_{0}, C_{H}\right] \\
& \text { Bimorph }=\text { Bimorph }\left[F_{Z}, E, f, D_{0}, C_{H}\right] \\
& \text { Radial Field Diaphragm }=\text { Radial Field Diaphragm }\left[F_{Z}, E, f, D_{0}, C_{H}\right]
\end{aligned}
$$

\section{Conclusions}

Several factors affecting the performance of piezoelectric diaphragms as synthetic jets are systematically studied. The parameters studied included actuator parameters such as driving signal, frequency, voltage and as well as cavity physical characteristics. Using the peak velocity as the response variable a fractional factorial design of experiments was performed individually for each diaphragm to test the level of significance of the factors studied. In case of the Thunder it was seen that the driving signal, orifice shape and cavity volume had a more significant effect on the velocity as compared to voltage and frequency. The results were verified using regression analysis. For the Bimorph the same analysis showed that all the factors were important with the voltage being most important. The RFD analysis showed similar results to the Bimorph however because of inconsistencies on the results no significant conclusions can be made. 


\section{Acknowledgments}

The author thanks NASA Langley Research Center for their financial support and technical assistance through contract number NNL04AA04G.

\section{References}

${ }^{1}$ Gad-el Hak, M., "Flow Control: Passive, Active, and Reactive Flow Management,” Cambridge University Press, Cambridge, United Kingdom, 2000.

${ }^{2}$ Pack, L. G. and Joslin, R. D., “Overview of Active Flow Control at NASA Langley Research Center,” Proceedings SPIE Smart Structures and Materials, San Diego, CA, March, 1998.

${ }^{3}$ Bewley, T. R., "New Frontiers for Control in Fluid Mechanics: A Renaissance Approach," Proceedings of the 3rd ASME/JSME Joint Fluids Engineering Conference, Symposium on Control of Wall-Bounded and Free-Shear Flows, eds. L.D. Kral and T. Shakouchi, ASME Paper No. FEDSM99-6926, San Francisco, CA, July 1999.

${ }^{4}$ Donovan, J. F., Kral, L. D., and Cary, A. W., “Active Flow Control Applied to an Airfoil,” AIAA Aerospace Science Meeting, Reno, NV, Paper No. 98-0210, January 1998.

${ }^{5}$ Smith, B. L. and Glezer, A., "Vectoring and Small-Scale Motions Effected in Free Shear Flows Using Synthetic Jet Actuators,” 35th AIAA Aerospace Sciences Meeting, Reno, NV, Paper No. 97-0213, 1997.

${ }^{6}$ Seifert, A., Bachar, T., Koss, D., Shepshelovich, M., and Wyganski, I., “Oscillatory Blowing: A Tool to Delay BoundaryLayer Separation,” AIAA Journal, Vol. 31, No. 11, pp.2052-2060, 1993.

${ }^{7}$ Seifert, A. and Pack, L. G., "Oscillatory Control of Separation at High Reynolds Numbers,” AIAA Paper No. 98-0214, 1999.

${ }^{8}$ Smith, B.,L., "Synthetic Jets and their Interaction with Adjacent Jets,” PhD Dissertation, Mechanical Engineering Dept., Georgia Institute of Technology, Atlanta, GA, June, 1999.

${ }^{9}$ Kral, L. D. and Guo, D., 1999, “Characterization of Jet Actuators for Active Flow Control,” 30th AIAA Fluid Dynamics Conference, Norfolk, VA, Paper No. 99-3573, June, 1999.

${ }^{10}$ Smith, D. R., Kibens, V., Parekh, D. E., and Glezer, A., “Thrust-Vectoring with Hybrid Synthetic Jet Actuators," Proceedings of the 1997 ASME Fluids Engineering Division Summer Meeting, Forum on High Speed Jet Flows, Vancouver, B.C., Paper No. FEDSM97-3679, June, 1997.

${ }^{11}$ Amitay, M., Honohan, A., Trautman, M., and Glezer, A., "Modification of the Aerodynamic Characteristics of Bluff Bodies Using Fluidic Actuators,” 28th AIAA Fluid Dynamics Conference, No. 97-2004, 1997.

${ }^{12}$ Amitay, M., Kibens, V., Parekh, D. E., and Glezer, A., "Flow Reattachment Dynamics over a Thick Airfoil Controlled by Synthetic Jet Actuators”, 37th AIAA Aerospace Sciences Meeting, Reno, NV, Paper No. 99-1001, January, 1999.

${ }^{13}$ Amitay, M. and Glezer, A., “Aerodynamic Flow Control of a Thick Airfoil using Synthetic Jet Actuators,” Proceedings of the 3rd ASME/JSME Joint Fluids Engineering Conference, Symposium on Control of Wall-Bounded and Free-Shear Flows, eds. L.D. Kral and T. Shakouchi, ASME Paper No. FEDSM99-6922, San Francisco, CA, July 1999.

${ }^{14}$ Smith, D. R., Amitay, M., Kibens, V., Parekh, D. E., and Glezer, A., "Modification of Lifting Body Aerodynamics using

Synthetic Jet Actuators,” 36th AIAA Aerospace Sciences Meeting, Reno, NV, Paper No. 98-0209, January, 1998.

${ }^{15}$ Smith, B. L., Trautman, M. A., and Glezer, A., “Controlled Interactions of Adjacent Synthetic Jets,” 37th AIAA Aerospace Sciences Meeting, Reno, NV, Paper No. 99-0669, 1999.

${ }^{16}$ Smith, B. L. and Glezer, A., “The Formation and Evolution of Synthetic Jets,” Physics of Fluids, Vol. 10, No. 9, pp. 22812297, 1998.

${ }^{17}$ Jordan, L., Ounaies, Z., Tripp, J. and Tcheng, P., "Electrical properties and power considerations of a piezoelectric actuator,” NASA/CR-2000-209861, ICASE Report No. 2000-8, 2000.

${ }^{18}$ Lalande, F., Chaudhry, Z., and Rogers, C., "A Simplified Geometrically Nonlinear Approach to the Analysis of the Moonie Actuator,” IEEE Transactions on Ultrasonics, Ferroelectrics, and Frequency Control, Vol 42 No1, January, 1995.

${ }^{19}$ Shih, W., Y., Shih, W., H., and Aksay, I., A., "Scaling Analysis for the Axial Displacement and Pressure of Flextensional Transducers," Journal of American Ceramic Society, Vol 80 No5, pp1073-1078, 1997.

${ }^{20}$ Haertling, G., "Rainbow Acuators and Sensors: A New Smart Technology,” Proceeding of the SPIE Smart Structures and Materials, San Diego, Vol 3040, pp 81-92, 1997.

${ }^{21}$ Idogaki, T., Tominaga, T., Senda, K., Ohya, N., Hattori, T., "Bending and expanding motion actuators", Sensors and Actuators A, Vol 54, pp 760-764, 1996.

${ }^{22}$ Schwartz, R., W., Narayanan, M., "Development of high performance stress-biased actuators through the incorporation of mechanical pre-loads,” Sensors and Actuators A, Vol 101, pp 322-331, 2002.

${ }^{23}$ Ounaies, Z., Mossi, K., Smith, R., Bernd, J., "Low-Field and High-Field Characterization of Thunder Actuators," Proceedings SPIE Smart Structures and Materials, San Diego, Vol 4333, pp 399-407, 2001.

${ }^{24}$ Mossi, K., Bishop, R., “Characterization of Different Types of High Performance Thunder Actuators,” Proceedings SPIE Smart Structures Materials, San Diego, Vol. 3675, pp 738-743, 1999.

${ }^{25}$ Mossi, K., Selby, G., and Bryant, R., “Thin-Layer Composite Unimorph Ferroelectric Driver and Sensor Properties”, Materials Letters, Vol. 35, pp 39-49, 1998.

${ }^{26}$ Cappelleri, D., J., Frecker, M., I., Simpson, T., W., Snyder, A., "Design of a PZT Bimorph Actuator Using a MetamodelBased Approach,” Transactions of the ASME, Vol 124, pp 354-357, 2002. 
${ }^{27}$ Wang, Q., M., Zhang, Q., Xu, B., Liu, R., Cross, L., E., “ Nonlinear piezoelectric behavior of ceramic bending mode actuators under strong electric fields,” Journal of Applied Physics, Vol 86 No. 6, pp 3352-3360, 1999.

${ }^{28}$ Bryant, R., Effinger, R., IV, Copeland , B., Jr., 2002, “Radial Field Piezoelectric Diaphragms,” Actuator 2002, A1.3, June 2002.

${ }^{29}$ Bryant, R., Effinger, R., IV, Aranda, I., Jr., Copeland, B., Covington E., III, “Active Piezoelectric Diaphragms,” Proceedings of SPIE Smart Structures and Materials, San Diego, Vol. 4699-40, 2002.

${ }^{30}$ Mossi, K., Bryant, R., "Pre-stressed Circular Actuators”, American Ceramic Society, pp 445—454, 2004.

${ }^{31}$ Mossi, K., Bryant, R., “Synthetic jets for piezoelectric actuators”, Materials Research Society, pp 407-412, 2004.

${ }^{32}$ Mossi, K., Bryant, R., “Characterization of piezoelectric actuators for flow control over a wing”, Actuator 2004, pp 181185, 2004.

${ }^{33}$ Bryant, R. G., “LaRC ${ }^{\mathrm{TM}}$-SI: A Soluble Aromatic Polyimide,” High Performance Polymers, Vol 8(4), pp 607, 1996.

${ }^{34}$ Bryant, R. G., Effinger, R. IV, Aranda, I. Jr., Aranda, I. Jr., Copeland, B. M., Covington, E. W. III, and Hogge, J., "Radial Field Piezoelectric Diaphragms,” Journal of Intelligent Materials Systems and Structures, Vol 15, pp. 527-538, 2004.

${ }^{35}$ Montgomery, D., "Design and Analysis of Experiments,” 6th edition, John Wiley \& Sons, Hobeken, NJ, 2005.

${ }^{36}$ Cater, J., E. and Soria, J., “The evolution of round zero-net-mass-flux jets,” Journal of Fluid Mechanics. Vol. 472, pp. 167200, 2002.

${ }^{37}$ Zhong, S., Garcillan, L., Pokusevski, Z., Wood, N., J., “A PIV study of synthetic jets with different orifice shape and orientation,” 2nd AIAA Flow Control Conference, Portland, Oregan, AIAA 2004-2213, June, 2004. 